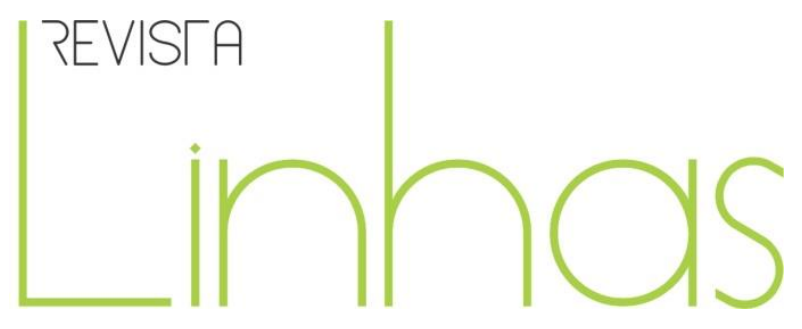

\title{
Contribuições de ações de formação contínua para a (trans)formação de professores universitários
}

\begin{abstract}
Resumo
A partir do entendimento de que a docência é uma profissão marcada por ambiguidades e singularidades que a distinguem como uma profissão complexa, a finalidade precípua desse artigo é compreender o processo de formação contínua de professores universitários em contexto de trabalho. Apoiadas nessa premissa, questionamos: as ações de formação contínua contribuem para a (trans)formação e a prática pedagógica de professores universitários? Apresentamos nossas interpretações oriundas de uma pesquisa realizada em estágio pós-doutoral, a qual nos permitiu compreender a repercussão de ações formativas realizadas em contexto de trabalho de professores universitários. Os sujeitos da pesquisa são professores que atuam em diversas áreas do conhecimento na Universidade Federal de Uberlândia - UFU/MG, e participaram de ações formativas na instituição, realizadas no período de 2013 a 2017. A análise qualitativa dos dados obtidos, a partir da interlocução com os professores, indicou que a docência é uma atividade complexa e exige formação permanente, específica, comprometida com singulares condições de exercício do magistério e, nesse sentido, consideramos que as ações formativas promoveram reflexões significativas para que eles compreendessem os processos de desenvolvimento profissional docente, indicando também que a formação contínua poderá incidir na qualidade de suas práticas. Consideramos necessária a constituição de uma política institucional na UFU que tenha como princípio a formação permanente, colaborativa, constituída no exercício cotidiano do trabalho docente, planejada e realizada de acordo com as necessidades formativas dos professores.
\end{abstract}

Palavras-chave: Formação Permanente. Desenvolvimento Profissional. Ações Formativas. Docência Universitária.

\section{Para citar este artigo:}

CAMPOS, Vanessa T. Bueno; ALMEIDA, Maria Isabel de. Contribuições de ações de formação contínua para a (trans)formação de professores universitários. Revista Linhas. Florianópolis, v. 20, n. 43, p. 21-50, maio/ago. 2019.

Vanessa T. Bueno Campos

Universidade Federal de Uberlândia

- UFU - Uberlândia/MG - Brasil vbcampos@ufu.br

Maria Isabel de Almeida Universidade de São Paulo - USP São Paulo/SP - Brasil mialmei@usp.br 


\title{
Contributions of continuous training actions for the (trans)training of university teachers
}

\begin{abstract}
From the understanding that teaching is a profession marked by ambiguities and singularities that distinguish it as a complex profession, the main purpose of this article is to understand the process of continuous training of university teachers in a work context. Based on this premise, we ask: do continuous training actions contribute to the (trans)formation and pedagogical practice of university professors? We present our interpretations from a postdoctoral research, which allowed us to understand the repercussion of training actions carried out in the context of the work of university professors. The subjects of the research are professors who work in several areas of knowledge at the Federal University of Uberlândia - UFU/MG, and participated in training actions at the institution, carried out from 2013 to 2017. The qualitative analysis of the data obtained, from the interlocution with teachers, indicated that teaching is a complex activity and requires permanent, specific training, committed to unique conditions of exercise of teaching and, in this sense, we consider that the formative actions promoted significant reflections so that they understood the processes of professional teacher development, also indicating that continuous training may focus on the quality of their practices. We consider necessary the constitution of an institutional policy in the UFU that has as principle the permanent, collaborative formation, constituted in the daily exercise of the teaching work, planned and realized according to the formative needs of the teachers.
\end{abstract}

Keywords: Permanent Formation. Professional Development. Training Actions. University Teaching. 


\section{Tornar-se professor: eis a questão}

O dilema metodicamente construído por Shakespeare, em seu memorável Hamlet, e sumariamente popularizado na expressão "ser ou não ser", é inesgotável tanto em sua capacidade de servir como material textual para montagens teatrais, quanto como fonte de inspiração para questionarmos as condições relativas à formação de professores universitários; ao parafrasear o dilema shakespeariano, pretendemos refletir, não só sobre a possibilidade de uma escolha entre ser ou tornar-se, mas confrontando as duas ações ao considerar que nos tornamos professores mediante a formação permanente.

A partir dessas reflexões, depreendemos que a opção por se tornar professor, quer seja na educação básica ou superior, exige formação. Não se nasce para ser professor ou professora e, constituir-se como tal, implica em apreender o percurso formativo, descobrir as relações e os modos como cada um ingressa e vive a docência, pois a formação profissional está intimamente relacionada às vivências e interações estabelecidas com o meio e com as pessoas que compartilham e interferem, de forma direta ou indireta, nesse processo.

No que se refere à especificidade de tornar-se professor universitário, bem como às condições de ingresso no magistério superior, destacam-se significativas reflexões sob diferentes enfoques sobre a importância (ou não) dos conhecimentos pedagógicos e epistemológicos que definem e caracterizam a docência. Essas discussões geram tensões que se tornam cada vez mais explícitas nas instituições de educação superior, porque o número de professores sem formação e experiência, específicas para a docência na qual ingressam, tem aumentado significativamente.

As pesquisas sobre Pedagogia Universitária, especificamente no que concerne à formação, à identidade, aos saberes e ao desenvolvimento profissional de professores universitários, em âmbito nacional e internacional, principalmente a partir da década de 1990, no século XX, se expandiram, delineadas por diferentes abordagens, revelando perspectivas diversas, concepções e enfoques que se configuram em espaço profícuo para o aprofundamento de estudos na área e abrangem um vasto campo temático: papel da pedagogia universitária para a prática do professor universitário; desenvolvimento profissional docente e formação inicial e contínua; desafios da docência universitária; 
inovações pedagógicas na educação superior; políticas públicas para o educação superior; práticas e relações pedagógicas, dentre outros.

No que se refere à formação de professores universitários, destacamos os estudos e pesquisas realizados por Behrens (2007), Cunha (2006, 2007, 2008, 2010), Pimenta e Anastasiou (2010, 2003), Veiga (2006), Campos (2010, 2017), Almeida (2011, 2012), Morosini (2001), Leite e Ramos (2012), Nóvoa (2002), Zabalza (2004), Fernández Cruz (2006), Garcia (1999; 2009), Imbernòn (2010), os quais, de forma geral, nos advertem para a inexistência de amparo legal que estimule a formação pedagógica dos professores que atuam na educação superior, aspecto que reflete a "cultura da desvalorização do pedagógico", evidenciando fragilidades teórico-prática na formação da pós-graduação stricto sensu, espaço que, por excelência e por exigência legal, deveria primar em oferecer subsídios para uma formação inicial e contínua de qualidade. Os estudos também apontam a necessidade de as IES assumirem e consolidarem políticas de formação pedagógica de docentes universitários, desenvolverem ações formativas constituídas a partir das necessidades docentes e valorizarem a produção científica dos docentes sobre o ensino e suas relações: aprendizagem, planejamento, avaliação, metodologias.

A profissão docente, quer seja exercida na educação básica ou na superior, é uma das profissões que mais tem recebido solicitações para manter-se atualizada e qualificada face à realidade social. Para isso, o investimento na continuidade dos estudos objetivando o desenvolvimento profissional tem sido imperativo e inevitável, embora, os processos formativos para professores universitários se constituam, historicamente, em ações pontuais, fragmentadas e distantes de suas necessidades formativas, com poucas contribuições para o desenvolvimento profissional docente. Por conseguinte, consideramos fundamental que as políticas de formação contínua nas IES promovam ações que colaborem com a formação permanente de docentes universitários, tomando como referência suas necessidades formativas.

A partir desses argumentos iniciais, nos propomos neste artigo, a analisar e discutir a repercussão de ações formativas para o desenvolvimento profissional de professores universitários, decorrentes de nossas interpretações de parte dos dados obtidos em uma pesquisa desenvolvida na Universidade Federal de Uberlândia, durante o 
estágio pós-doutoral ${ }^{1}$. Para tanto, questionamos: as ações de formação contínua contribuem para a (trans)formação e a prática pedagógica de professores universitários?

As respostas possíveis a essa questão foram obtidas a partir da análise qualitativa de amplo acervo de fontes bibliográficas, documentos oficiais, dados estatísticos, questionários, fontes impressas e fontes orais. Compartilhamos de concepções que ampliam o conceito de fontes, considerando o seu caráter de construção, sua historicidade e sua parcialidade, porque os documentos não falam por si, não são meros depositários do real, mas são evidências, registros da experiência pessoal e profissional dos sujeitos históricos que re/constroem cotidianamente os saberes e as práticas educativas na IFES estudada (CHARTIER, 1990; LE GOFF, 1998).

A pesquisa foi desenvolvida em três etapas: (1 $1^{a}$ ) levantamento bibliográfico, estudo da literatura a respeito de Pedagogia Universitária, Formação Contínua e Desenvolvimento Profissional Docente na Educação Superior; $\left(2^{\mathrm{a}}\right)$ análise dos documentos relativos às ações formativas realizadas pela Divisão de Formação Docente DIFDO/UFU; $\left(3^{\mathrm{a}}\right.$ ) construção dos dados relativos ao trabalho docente, formação inicial e contínua, saberes e práticas declarados por professores de diversas áreas de conhecimento que participaram de ações formativas na IFES no período de 2013 a 2016: i) questionário enviado on-line aos docentes que haviam totalizado mais de 3ohoras de participação em ações formativas para identificarmos a trajetória formativa e ingresso na docência; ii) entrevistas realizada com $25 \%$ dos professores que responderam ao questionário, para apreendermos as concepções docentes sobre o trabalho que realizam e a repercussão das ações formativas, a partir da compreensão deles, sobre a prática pedagógica.

O questionário foi elaborado usando o Google Forms², com itens relativos ao perfil dos sujeitos (idade, sexo, estado civil, tempo de docência, formação, etc.) e com questões para identificar a concordância e satisfação, no que se refere à formação inicial e contínua e contribuições das ações formativas. A devolutiva de questionários respondidos foi de $45 \%$ (58). Desse total, $25 \%$ (15) colaboraram na segunda fase, na qual

\footnotetext{
${ }^{1}$ Estágio pós-doutoral supervisionado pela Professora Dra. Maria Isabel de Almeida, realizado na Faculdade de Educação da Universidade - USP, São Paulo, no período agosto de 2016 a agosto de 2017.

${ }^{2}$ O Google Drive abriga o Google Forms para a confecção de formulários on-line. A página para elaboração de um questionário, em português, está disponível em: <https://www.google.com/intl/pt-BR/forms/about/>.
} 
foram realizadas entrevistas com uso de formulário semiestruturado. O grupo de entrevistados foi composto por dois docentes de cada área do conhecimento. Elaboramos um roteiro para que a condução das entrevistas e os objetivos do estudo pudessem ser alcançados. As informações consideraram: fonte social de aquisição do saber docente; os principais motivos que os levaram a ingressar na carreira docente de educação superior; o relato de experiências de aprendizagem para a docência no ensino superior em diferentes momentos da carreira profissional; os desafios enfrentados no exercício da docência universitária; as iniciativas consideradas importantes para enfrentar os desafios que surgem na docência; a contribuição das ações formativas investigadas na (re)elaboração de seus saberes pedagógicos; a troca de experiências com os pares; e o entendimento sobre o que seria o desenvolvimento profissional docente.

O conjunto de informações produzido pelos professores foi organizado com auxílio do software Nvivo ${ }^{3}$ para otimizar a composição do corpus de análise, em função da extensão do material obtido, que resultou em quadro analítico dos depoimentos de cada um dos sujeitos da pesquisa para cada uma das categorias: ingresso na docência, aprendizagem da docência, formação inicial, contínua, contribuições das ações formativas à prática didático-pedagógica e ao desenvolvimento profissional. Para compor o corpus no software, as temáticas foram analisadas por meio de seus respectivos recortes discursivos, objetivando apreender os discursos docentes e suas experiências em relação a cada temática, mas também procurando, nas análises, o entrecruzamento das narrativas, as singularidades, as diversidades, as contradições. Embora consideremos que os recursos disponíveis no software não substituam a leitura e a reflexão, eles contribuem para que as análises sejam mais completas e confiáveis (CAMPOS, 2017).

A partir dos dados, realizamos a análise de conteúdo inspirada na análise crítica dos discursos (BARDIN, 2000). Para tanto, apoiamo-nos em uma perspectiva crítica que considera as interações no processo de formação contínua e os significados explícitos e implícitos nos dados estatísticos e/ou nos discursos orais, ponderando a importância da subjetividade, isto é, os conhecimentos, experiências, contextos e visões de mundo dos sujeitos envolvidos na pesquisa, incluindo as pesquisadoras.

\footnotetext{
${ }^{3}$ Informações sobre o Nvivo podem ser obtidas em: <https://www.qsrinternational.com/nvivo/home>.
} 
Nesse sentido, na pesquisa realizada, nos fundamentamos na perspectiva dialética do materialismo histórico, e essa opção evidencia o nosso compromisso ético e político em relação à realidade, pois "para a verdadeira apreensão do real é preciso que o pensamento trabalhe o observável e vá além dele, concretizando-o por meio da consciência que é ativa, não por um dom sobrenatural, mas porque abstrai e apreende o movimento existente na totalidade" (FRANCO, 1999, p. 213).

A pesquisa nos permitiu compreender que a docência é uma atividade complexa e que exige formação rigorosa, comprometida com singulares condições de exercício do magistério e, tal processo não deve ser pensado apartado das condições objetivas do contexto do trabalho docente e da situação organizacional da instituição como um todo. É preciso entender o processo de formação docente contínua a partir de suas múltiplas dimensões: sociais, econômicas, históricas, em que os docentes estão inseridos no âmbito educacional, como também, as condições objetivas para que a formação contínua se configure no contexto das IES.

\section{Tornar-se professor: formações para a Docência Universitária}

A função da universidade passa por mudanças. Há, no imaginário social, cada vez mais, a atribuição de um valor peculiar ao conhecimento, no qual a universidade acumula dupla tarefa: a de produzir e disseminar os conhecimentos nas diferentes áreas, e a de formar profissionais para atender as demandas sociais e econômicas. Tantas mudanças no cenário político e econômico provocam demandas e desafios que dificultam o trabalho docente, geram insatisfações e evidenciam que o exercício da docência não é algo simples. A esse respeito, Imbernón (2016, p. 13-14), pondera que:

[...] a mudança inunda tudo, parece que tudo vai mudar, exceto a mudança [...] assim, sem mais nem menos, a mudança é incorporada ao papel escrito e às declarações públicas e políticas como um lugar-comum, mas que dificilmente se vê transferido para a realidade da prática da educação [...] são necessárias muitas mudanças para mudar a educação. 
Os discursos sobre a necessidade e a urgência de mudanças na Educação Superior, no que se refere à formação de professores universitários, são recorrentes e sublinham a exigência da qualidade, contudo, em face da complexidade inerente ao exercício da docência, Imbernón (2016, p. 14 e 22) considera que a formação deveria ser pensada e efetivada a partir da relação dinâmica entre a realidade histórica e a totalidade concreta em que atuam os docentes e isso exige, segundo o autor:

[...] perguntar-se como estabelecer relações com a comunidade e com os docentes; a modificação das estruturas, as políticas educacionais, o currículo, o papel dos alunos, a nova forma de aprender para além da escolarização [...] sobretudo implica romper certas inércias e ideologias institucionais [...] políticas conservadoras, neoconservadoras, neoliberais. (IMBERNÓN, 2016, p. 14)

Diante dessa realidade, é outorgada à Universidade a responsabilidade de construir e assumir um projeto pedagógico que viabilize uma consistente formação teórico-prática aos seus próprios professores, no sentido de contemplar as diferentes dimensões - científica, cultural, humana, política, técnica e ética -, para que possam se tornar profissionais capazes de atuar criticamente na sociedade, no sentido de contribuírem com a formação dos estudantes na graduação e pós-graduação. Contudo, se por um lado, os docentes, são desafiados a relacionarem saberes científicos com saberes didáticos, e a possibilitar o processo de ensino-aprendizagem, por outro lado, as novas exigências de um mercado de trabalho mais competitivo, modificaram o perfil dos estudantes que ingressam cada vez mais jovens na universidade e almejam uma formação em curto prazo, e que favoreça a aquisição de conhecimentos de forma condensada em exíguo tempo.

A docência universitária, nessa perspectiva, é uma profissão cuja complexidade requer conhecimentos epistemológicos específicos, incorporados no processo do fazer docente, que só têm sentido quando compreendemos o campo em que as práticas pedagógicas se constituem e são constituídas. Quanto mais sejamos capazes de refletir sobre a realidade vivida, experienciada, mais condições teremos de agir sobre ela, assumindo o compromisso de mudá-la, pelo fato de sentirmo-nos inseridos, partícipes, 
produtivos nela: “[...] mudam os que se comprometem com a mudança” (IMBERNÓN, 2016, p. 22).

Por conseguinte, é necessário compreendermos o processo de construção de saberes e fazeres em uma perspectiva dialética. É essencial, tal como propõem Rodrigues e Esteves, identificarmos a natureza da docência vinculada à formação inicial e contínua:

[...] A formação não se esgota na formação inicial, devendo prosseguir ao longo da carreira, de forma coerente e integrada, respondendo às necessidades de formação sentidas pelo professor e às do sistema educativo, resultantes das mudanças sociais e/ou do próprio sistema de ensino. Não se trata, pois, de obter uma formação inicial, válida para todo o sempre [...] a formação contínua é aquela que tem lugar ao longo da carreira profissional após a aquisição da certificação profissional inicial privilegiando a ideia de que a sua inserção na carreira docente é qualitativamente diferenciada em relação à formação inicial. (RODRIGUES E ESTEVES, 1993, p. 41-45)

Complementando as proposições das autoras, Nunes afirma que a formação docente é um processo em permanente:

[...] (des)construção de conceitos e práticas para corresponder às exigências do trabalho e da profissão docente [...] a formação contínua insere-se, não como substituição, negação ou mesmo complementação da formação inicial, mas como um espaço de desenvolvimento ao longo da vida profissional do professor, comportando objetivos, conteúdos, formas organizativas diferentes daquela, e que tem seu campo de atuação em outro contexto (NUNES, 2000, p. 17)

O trabalho formativo - no sentido de constituir-se, de tomar forma, como observa Ferry (2004), para atuar, refletir e aperfeiçoar - será expressão da consciência crítica, orientada para a práxis enquanto atividade social transformadora. A formação, nesse sentido, deve ser pensada de modo integral e contínuo e que não esteja restrita em si mesma, mas que é constituída de múltiplas formações que exigem a condição permanente de aprender, desaprender e tornar a aprender para interpretação da realidade, ampliar visão de mundo e alcançar a práxis. A ação de (re)aprender os saberes 
específicos da docência para (trans)formar, com a perspectiva de alcançar a práxis é constante, ou seja, trata-se de um processo em contínuo desenvolvimento.

As propostas de formação, conforme Marin (1995; 2003), deveriam partir do pressuposto da educabilidade do ser humano em um percurso formativo continuum, o qual revela a nossa incompletude, o nosso inacabamento; deveria nos (trans)formar de modo que as ações educativas reverberassem nas interações do e no espaço escolar, independentemente do nível de ensino, enquanto possibilidade de troca, de (re)construção de novos conhecimentos e emancipação. A formação contínua é um espaço de interação entre as dimensões pessoais e profissionais, no qual, aos professores é permitido apropriarem-se dos próprios processos de formação e dar-lhes um sentido no quadro de suas histórias de vida.

A formação contínua, na acepção de Garcia (1999), é um trabalho do professor sobre si mesmo, porque é, eminentemente, um processo de autoformação e interformação que envolve as experiências vivenciadas pelos professores, suas histórias de vida, seus interesses, crenças e valores bem como as experiências oriundas das interações com aqueles que fazem parte de sua trajetória de vida, isto é, um processo a um só tempo, individual e coletivo, que ocorre a partir de necessidades reais, contextualizadas no espaço-tempo de sua atuação profissional.

O desenvolvimento profissional docente está imbricado ao conceito de formação contínua e deve ser entendido como atitude permanente de indagação, de formulação de questões e busca de soluções a respeito dos desafios que, cotidianamente, permeiam a vida pessoal e profissional dos professores. Se o docente compreender o seu agir profissional como um processo em desenvolvimento, se disporá a refletir sobre suas próprias vivências, a analisar suas opções teóricas e metodológicas, a rever suas práticas, reelaborá-las, criar outras novas e seguir desenvolvendo-se profissionalmente como docente.

Com essa postura, o professor está produzindo sua professoralidade, o que implica não só em dominar conhecimentos, saberes, fazeres de determinado campo, mas também na sensibilidade em termos de atitudes e valores que levem em conta os saberes da experiência. A experiência deve ser entendida a partir da reflexão sistemática na qual 
o foco está nas relações interpessoais, componente intrínseco ao processo de ensinar, aprender, formar-se e, consequentemente, desenvolver-se profissionalmente.

A formação é processo, no qual estão imbricadas múltiplas dimensões, em permanente mudança e desenvolvimento e deve ser apreendido, tal como propõe poeticamente Meireles (1999, p. 1443): “Hoje desaprendo o que tinha aprendido ontem e que amanhã recomeçarei a aprender. Todos os dias desfaleço e desfaço-me em cinza efêmera: todos os dias reconstruo minhas edificações, em sonho eternas".

Essa perspectiva nos permite entender que somente com a permanente (re)elaboração de seus saberes e práticas, os professores conseguirão desenvolver-se para melhor desempenharem o trabalho docente. É necessário, no entanto, ponderar que o desenvolvimento profissional dos professores universitários, além de suas características idiossincráticas, também depende de fatores que constituem o contexto e condições objetivas do trabalho docente.

A construção da aprendizagem para se tornar professor, nessa perspectiva, deve ser colaborativa, constituída no exercício cotidiano do trabalho que realizam nas IES. É uma conquista social, compartilhada, que envolve trocas, cooperação, com vistas a alcançar a qualidade dos processos formativos.

As IES, em nossa opinião, também são responsáveis pelo modo como se desenvolve o trabalho dos professores, principalmente daqueles que estão na fase inicial de suas carreiras e merecem atenção especial; a constituição de espaços de formação que os impulsionem à reflexão e à problematização de modo coletivo e compartilhado pode se configurar em ação formativa e, por conseguinte, em desenvolvimento profissional docente.

\section{Ações formativas na UFU: contribuições à (trans)formação e ao desenvolvimento profissional de professores universitários}

O debate sobre a instituição de políticas de formação de docentes universitários em contexto de trabalho, nas IES, não é algo simples, uma vez que envolve a discussão do papel social da instituição, dos pressupostos teórico-metodológicos da produção do conhecimento e dos impactos relacionados às diretrizes emanadas de outros órgãos 
gestores que definem processos de avaliação da produtividade daqueles que vivem a universidade e que a fazem no seu cotidiano. Assim, o desafio que se apresenta às instituições educacionais é o de organizar cursos de formação contínua, nos quais os professores sejam considerados partícipes do processo formativo. Outro desafio será o de reconhecer que medidas simplistas não são capazes de resolver questões complexas, ou seja, será preciso instituir processos formativos baseados em princípios que realmente possibilitem uma formação teórico-prática capaz de munir os professores com diferentes saberes profissionais para o exercício da docência. A esse respeito, Pimenta e Anastasiou, destacam que:

[...] embora o sistema não se preocupe com a profissionalização dos docentes e não estabeleça princípios e diretrizes para a profissionalização dos docentes do ensino superior, realiza uma série de verificações externas sobre a docência: os resultados que os alunos têm no provão, os índices de professores com mestrado e doutorado nas instituições [...]. Assim, o Estado avaliador, aparentemente desconhecendo as funções da universidade como instituição social, estabelece os parâmetros, cabendo às instituições prover formas de profissionalizar seus professores, o que ocorrerá conforme a visão do que seja profissionalização. (PIMENTA E ANASTASIOU, 2010, p. 149)

Nessa direção, destacamos o trabalho realizado pela Divisão de Formação Docente - DIFDO, vinculada à Diretoria de Ensino e Pró-Reitoria de Graduação da UFU, no período de 2013 a 2016, que desenvolveu projetos e ações multi e interdisciplinares, dentre os quais salientamos: as Rodas de Conversa; os Cursos de Docência Universitária, a Revista on-line DiversaPrática, os Fóruns Internacionais sobre Prática Docente Universitária, Oficinas e Minicursos.

Na UFU, no período observado, havia 1.738 professores efetivos, sendo que 607 (34,8\%) participaram voluntariamente das ações formativas realizadas pela DIFDO. Consideramos expressiva a adesão voluntária, principalmente nas ações "roda de conversas" (218 professores/as) e nos "cursos de docência universitária" (213 professores/as).

As Rodas de Conversa objetivaram proporcionar um espaço de interlocução e formação contínua. Os/as professores/as, ao longo de onze encontros, explicitaram suas dificuldades, suas angústias e indicaram a necessidade de ampliar os espaços para 
discutirem sobre suas práticas, para trocarem experiências e realizarem reflexões coletivas que promovessem o aprofundamento das questões teórico-metodológicas, consideradas por eles, indispensáveis à reflexão sobre a prática pedagógica, embora mais pautada na dimensão técnica do ensino.

Consideramos que os processos formativos deverão ser construídos, planejados e desenvolvidos a partir das necessidades formativas dos professores, conforme destaca Murillo (2005), ou seja, uma formação pautada na concepção colaborativa, em que os professores estejam diretamente envolvidos. Essa proposição teórico-metodológica defende que a formação é um processo que se realiza "com" os professores e não "para" eles.

Identificadas as principais demandas docentes, a DIFDO organizou e desenvolveu os cursos de "Docência Universitária". Os cursos foram oferecidos semestralmente, no período 2013 a 2017, em 10 módulos de 3h, em encontros quinzenais, nas modalidades presencial e a distância - para atender os docentes dos outros campi da UFU 4 . Participaram 213 professores, sendo que 35\% deles ingressaram na instituição no período, e, $65 \%$ já estão há mais tempo na IFES, com o objetivo de promover o desenvolvimento profissional docente, mediante a apreensão de diferentes saberes que contribuíssem para a melhoria da prática pedagógica.

Optamos por analisar as concepções dos professores que participaram dos Cursos de Docência Universitária e de outras ações formativas promovidas pela DIFDO, que totalizassem mais de $30 \mathrm{~h}$ de atividades, objetivando identificar as possíveis contribuições ao desenvolvimento profissional e se as ações desenvolvidas suscitariam discussões, análises e reflexões que pudessem reverberar na prática pedagógica; a escolha também se deu pela condição de estarem reunidas nos cursos expressivas quantidades de docentes de diversas áreas do conhecimento.

Para alcançarmos os objetivos propostos, usamos três instrumentos de coleta de dados: i) documentos da DIFDO com registros das diversas ações formativas e dos cursos de Docência Universitária; ii) questionário enviado on-line para 127 docentes que haviam totalizado mais de $30 \mathrm{~h}$ de atividades promovidas pela DIFDO para identificarmos a

\footnotetext{
${ }^{4}$ A Universidade possui três campi fora de sede: Campus Pontal em Ituiutaba, Campus Monte Carmelo e Campus Patos de Minas.
} 
trajetória formativa e ingresso na docência; iii) entrevistas realizadas com $25 \%$ dos professores que responderam ao questionário, para apreendermos as concepções docentes sobre o trabalho que realizam e a repercussão das ações formativas, a partir da compreensão deles, sobre a prática pedagógica.

A compilação dos dados obtidos em 58 dos questionários respondidos (45,6\%) e a análise das entrevistas realizadas com 15 professores (25\%), evidenciou que os docentes participaram das seguintes ações formativas: Cursos de Docência Universitária (100\%); Rodas de Conversa (50\%), Programa de Televisão (11,1\%), Fóruns Internacionais de Docência Universitária (22,2\%), Oficinas (44,4\%), Minicursos (27,8\%). Dentre as ações, os docentes destacaram que os Cursos de Docência Universitária foram os melhor corresponderam à expectativa de formação contínua.

Apresentamos, a partir da triangulação dos dados encontrados nos documentos, questionários e entrevistas analisados, as nossas interpretações para alcançar intelecção com o objeto de pesquisa. A análise documental e dos questionários nos possibilitou compreender o fenômeno investigado em uma perspectiva mais abrangente, enquanto a interlocução com os professores nas entrevistas evidenciou as especificidades articuladas à dimensão macro, sem, no entanto, desconsiderar as singularidades de cada depoimento.

Os professores que colaboram com a pesquisa dedicam 40 horas de trabalho semanais exclusivamente à UFU. A maior parte deles são mulheres (57\%), sendo que homens concentram-se em maior número nos cursos das áreas das ciências agrárias, exatas, da terra e engenharias. Os cursos em que preponderaram as mulheres são os das áreas das ciências biológicas, saúde, sociais aplicadas, humanas e linguística.

Observamos que, do total da amostra, a maior parte dos docentes é das áreas das ciências biológicas (8\%), engenharias (16\%), saúde (16\%) e sociais aplicadas (16\%); e também das áreas das ciências agrárias (13\%), exatas e da terra (11\%), humanas (7\%) e linguística (4\%).

Na amostra, verificamos, com relação à formação inicial, que a maioria (70\%) cursou bacharelado, enquanto aqueles que cursaram licenciatura (13\%) e a modalidade de licenciatura/bacharelado (16\%) estão em menor número. Com relação à formação na pós- 
graduação, $45 \%$ dos professores cursou doutorado, 26\% mestrado, $15 \%$ pós-doutorado e 12\% pós-graduação lato sensu. No que se refere ao acesso aos conhecimentos pedagógicos na pós-graduação stricto sensu, específicos à ação docente na educação superior, todos declaram ter sido irrisório ou inexistente.

Os professores podem ser considerados “jovens", pois estavam, em maior número, na faixa etária compreendida entre 31 e 46 anos e já lecionavam na UFU havia entre 4 e 11 anos. Interessante pensarmos que esse grupo de professores realizou a formação na educação básica e superior a partir dos anos 80, no século XX, e foi envolvido, de forma direta ou indireta em diversos momentos de transformação na sociedade brasileira como, por exemplo, a aprovação da Constituição Brasileira de 1988, ou as significativas mudanças na Lei de Diretrizes e Bases da Educação Brasileira extinção da LDB 5692/71 e promulgação da LDB 96394/96 -, eleições diretas, entre outros, o que nos leva a compreender a repercussão do percurso formativo na opção pela docência na educação superior.

A partir dessa análise, identificamos no estudo realizado por Sikes (1985) e Hubermam (1995), a relação entre as faixas etárias com as características pessoais e profissionais dos professores. A partir das proposições dos autores podemos sintetizar em cinco etapas tal relação, sendo que a primeira abrange a idade entre os 21 e os 28 anos, na qual os professores indicam maior preocupação com a indisciplina em sala de aula e o domínio dos conteúdos. A segunda acontece entre os 28 e os 33 anos, com interesse maior para a competência na ação didática. A terceira fase ocorre entre 30 e 40 anos, definida pela confiança, interesse e desenvolvimento profissional do professor. Entre os 40 e os 50/55 anos é a fase de maturidade profissional e a última fase vai dos 50 aos 55 anos até a aposentadoria, marcada pelo afrouxamento disciplinar.

Nessa perspectiva, seria interessante se as ações de formação contínua dos professores considerassem as diferentes fases da carreira docente, situando as necessidades formativas dos professores em relação às preocupações que caracterizam essas fases, bem como às especificidades dos diversos contextos em que eles desenvolvem o seu trabalho, não com concepção linear entre as fases, mas observando os seus movimentos e descontinuidades, já que a carreira docente é um processo e não 
uma série de atividades. Implica, inclusive, em compreendermos os impactos da experiência docente pregressa ao ingresso na UFU.

A experiência docente pregressa ao ingresso na UFU, principalmente nas IES da rede pública e particular, foi identificada pelos professores como relevante ao processo de aprendizagem da docência na educação superior, embora segundo as declarações de $80 \%$ deles, o aprendizado da profissão docente ocorreu de forma drástica, porque além de não terem recebido na formação inicial a fundamentação teórica voltada para esse fim, também não tiveram contato na pós-graduação com conhecimentos pedagógicos que lhes permitissem compreender a complexidade da profissão docente na educação superior. Afirmaram que aprenderam “como" ensinar na experiência cotidiana da sala aula, valendo-se da memória sobre as experiências vividas enquanto estudantes e reconheceram a necessidade de múltiplos conhecimentos para o exercício da profissão. No entanto, mesmo admitindo que as suas fragilidades formativas estivessem relacionadas à ausência de conhecimentos e competências do campo pedagógico, permaneceram convictos de que o domínio dos conhecimentos específicos de sua área se constitui como principal esteio do ensino.

A docência edifica-se por meio das concepções educacionais que fundamentaram a formação do professor e a sua maneira de atuar são reflexos de suas crenças, que agem como filtro ou como barreiras "[...] quanto mais antiga seja uma crença, mais difícil é mudá-la. As novas crenças são mais vulneráveis à mudança” (VAILLANT; MARCELO GARCIA, 2012, p. 55).

De acordo com Cunha (2006, 2010), as crenças estão alicerçadas em construtos históricos que projetam a docência com base quase exclusiva no domínio do conhecimento específico, pois há a expectativa de que o professor seja, cada vez mais, um especialista em sua área, tendo se apropriado, com o concurso da pós-graduação stricto sensu, do conhecimento legitimado academicamente no seu campo científico.

Os programas de pós-graduação, em especial os stricto sensu, embora explicitem nos seus objetivos a "preparação" para docência, conforme definição do artigo 66 da LDB 9.394/96, notadamente privilegiam a formação de pesquisadores para áreas específicas, enquanto o artigo 65 exclui a necessidade de prática de ensino para atuar nesse nível. 
Na Lei de Diretrizes e Bases da Educação Brasileira n 9.394/96, a formação dos professores universitários é tratada de forma pontual e superficial, se levarmos em consideração que, para atuar na educação básica, há exigências de formação em cursos de licenciatura, com carga horária mínima de 400 horas de prática educativa ao longo do curso, mais 400 horas de estágio curricular obrigatório, acrescidos de, pelo menos um quinto da carga horária total do curso, de conteúdos pedagógicos (BRASIL, 2015).

No conjunto das atividades oferecidas e nos requisitos dos programas de pósgraduação, os estudos sobre a prática e o próprio exercício da docência ocupam espaço ínfimo. Em geral, a "preparação" para a docência fica a cargo das atividades do Estágio de Docência ou da disciplina (quando ela é oferecida), denominada Metodologia do Ensino Superior ou Didática do Ensino Superior, com carga horária média de 64 horas/aula. Apesar do irrisório número de aulas, no conjunto das atividades previstas nos programas de pós-graduação, essa disciplina ocupa, segundo os dados encontrados na pesquisa, um importante papel na inserção dos professores da educação superior no campo dos estudos pedagógicos, embora a expectativa inicial dos docentes participantes da pesquisa estivesse mais centrada em métodos e técnicas.

O Estágio de Docência ou as disciplinas “pedagógicas”, com carga horária irrelevante, podem contribuir para suscitar a importância da formação profissional para a docência, mas entendemos, juntamente com Almeida (2011, 2012), Almeida e Pimenta (2009), Pimenta e Anastasiou (2010), que tal formação não pode se resumir ao treinamento didático. Tampouco ocorre automaticamente e em decorrência das habilidades de investigação que o pós-graduando desenvolve no mestrado ou no doutorado, conforme explicita Soares e Cunha (2010).

E por que não? Isso se explica em razão da complexidade da atividade docente, a qual demanda saberes específicos, assim como mantém sua multiplicidade, independentemente da área específica à qual o professor se vincula e atua, seja ela a pedagogia, a enfermagem, a história, as engenharias, etc. (ALMEIDA, 2012; CUNHA, 2006; 2007; 2008; PIMENTA, ALMEIDA, 2011, 2009). Por isso mesmo, a profissão docente requer construção ininterrupta de saberes e fazeres, posto que a sua atividade é permeada por condicionantes sociais, culturais, políticas, institucionais, profissionais e pessoais. 
Pesquisa realizada por Campos (2010) revelou que, se por um lado há a formação em programas de pós-graduação no Brasil, a formação pedagógica é preterida e é um hiato na formação e na profissionalização do professor universitário, revelando a fragilidade na constituição identitária, por outro lado, isso evidencia a importância de as universidades constituírem espaços para discussão e reflexão a respeito da formação para a docência e dos desafios enfrentados no exercício da profissão docente, com o objetivo de promover o entendimento a respeito do sentido formativo da instituição e do compromisso dos docentes com a melhoria da qualidade do ensino e da formação pessoal e profissional dos estudantes.

Consideramos importante ressaltar que a nossa compreensão de "qualificar o ensino" é tal qual propõe Rios (2002, 2009), ou seja, é a prática docente competente, de uma qualidade que se quer cada vez melhor, uma vez que está sempre em processo. Contudo, é preciso ter clareza de que o que se qualifica como "bom" tem um caráter cultural e histórico e é importante explicitar os seus critérios e fundamentos. Para indagar sobre a consistência dos critérios, faz-se necessária uma constante atitude crítica, que contribui para elucidar a prática docente competente e apontar suas dimensões: técnica, política, estética, ética e humana.

Os professores, durante as entrevistas, reconheceram que são também responsáveis pela formação de futuros profissionais nas diferentes áreas, inclusive de professores para a educação básica, contudo, embora 100\% dos docentes tenham reconhecido a importância e necessidade da formação continua, eles relatam que a formação para a docência não tem sido valorizada pela maioria das IES e nem pelas políticas voltadas para a educação superior. Avaliaram que as ações realizadas na UFU são importantes, porém tímidas, e foram unânimes ao reconhecerem a necessidade de uma política institucional que garanta efetivamente a formação contínua que qualifique o trabalho docente, viabilize condições objetivas do trabalho, contribua para a promoção da carreira e o reconhecimento do papel social, político, cultural do trabalho docente na qualificação do ensino, pesquisa, extensão.

Alguns professores, ao relatarem sobre seus percursos formativos e sobre a opção pela docência, reconheceram no processo de formação contínua dimensões importantes da construção de suas identidades docentes, pois ao longo dos cursos de 
Docência Universitária, compreenderam que a aprendizagem da docência deve ter como objetivo o desenvolvimento de uma estrutura, tanto ideológica como pedagógica, que sustente a construção da identidade profissional.

A partir da análise dos dados relativos aos registros de presença nas diversas ações realizadas pela DIFDO (2013 a 2016), bem como das declarações obtidas nas entrevistas com os docentes, identificamos que os encontros nos Cursos de Docência Universitária e nas demais ações formativas, tiveram frequência constante dos participantes e a organização e o desenvolvimento das atividades contribuíram para que eles interagissem com os colegas, com momentos de exposição intercalados com debates, oficinas, avaliações e relatos de experiências.

Afirmaram que as temáticas propostas foram satisfatórias e oportunas, desenvolvidas com a contribuição de professores especialistas em educação superior e destacaram que a diversidade de formações e experiências profissionais dos colegas de curso enriqueceram os debates e contribuíram para ampliar a compreensão da docência universitária. Além do mais, o contato com outros docentes possibilitou uma maior reflexão quanto aos temas e assuntos que envolvem o meio acadêmico universitário.

As temáticas mais relevantes, de acordo com os docentes, foram aquelas que oportunizaram a compreensão das técnicas e recursos de ensino, formas de avaliar e organizar o processo de ensino-aprendizagem. Não obstante a recorrente expectativa por uma técnica de ensino que consiga ensinar tudo para todos, nossos interlocutores, em busca da "técnica perfeita", identificaram ao longo do Curso de Docência Universitária que não existem receitas ou manuais para a solução dos problemas vivenciados ao longo da profissão docente.

Embora não tenham explicitado, identificamos na interlocução com os professores a recorrente dificuldade de assumirem a docência como atividade profissional e não como dom, ofício ou missão; dificuldade de compreenderem que a docência exige formação específica e, além disso, formação contínua e reflexão individual, coletiva, permanente; dificuldade de agregarem novos papéis à atividade docente, como o da pesquisa, da extensão, até mesmo papéis administrativos (como, por exemplo, a busca de financiamentos a projetos), dentre outros. Os dilemas que envolvem a profissionalização docente geram contradições e antagonismos no que se refere à 
formação que o professor deve ter, quais são os saberes, os conhecimentos necessários para atender à demanda exigida pelas instituições de ensino.

No âmbito da cultura universitária brasileira ainda persiste a crença de que basta que os professores tenham um diploma de mestre ou doutor para exercerem a docência. Em qualquer área de atuação, o conhecimento profissional representa o conjunto de saberes que habilita o indivíduo para o exercício de sua profissão, que o torna capaz de desenvolver suas funções. Todavia, a formação para profissão docente, no que se refere às atribuições inerentes à docência na educação superior, pode ser reconhecida, segundo Morosini (2001), como um território de tímidas iniciativas, com a inserção de profissionais de diversas áreas do conhecimento na prática docente sem uma formação que Ihes possibilite um trânsito menos intuitivo e acrítico no trabalho realizado.

Em geral, esses profissionais são impelidos a "formarem-se" professores na urgência do cotidiano, compreendendo a docência como uma atividade que se "aprende fazendo" e sustentada pelos saberes específicos oriundos do "mundo do trabalho". Entretanto, a esse respeito Freire afirma que:

A melhora da qualidade da educação implica a formação permanente dos educadores. $\mathrm{E}$ a formação permanente se funda na prática de analisar a prática. É pensando sua prática, naturalmente com a presença de pessoal altamente qualificado, que é possível perceber embutida na prática uma teoria não percebida ainda, pouco percebida ou já percebida, mas pouco assumida. (FREIRE, 2001, p. 72, 205)

A reflexão sobre a formação de professores enquanto mediadora do desenvolvimento profissional docente deve considerar, além das especificidades da profissão, a sua complexidade, presente em dinâmicas e processos específicos, na cultura universitária, porque é difícil pensar a formação docente enquadrada em um modelo previsível, padronizado, único e que pode ser aplicado em contexto diverso e, por isso é necessário apreendê-la, tal como propõe Campos (2017, p. 43), "em sentido plural, formações, porque a formação inicial é também a formação contínua, considerando que estas se interligam, orientando o percurso formativo ao longo da carreira profissional". 
A docência exige formação plural, pois envolve diferentes dimensões que se articulam: deve integrar a formação acadêmica (científica, literária, artística etc.) com a formação pedagógica; precisa ter como foco a formação de profissionais; se configura como formação de formadores e, como tal, exige o isomorfismo entre essa formação e a prática profissional que visa formar (GARCIA, 1999).

Processos formativos implicam na constituição de ações formativas para a docência nas quais os sujeitos se envolvem, buscando a construção de uma maneira de tornarem-se professores. As ações formativas estão ligadas à trajetória pessoal e profissional dos sujeitos, bem como às necessidades identificadas nesses percursos.

No que diz respeito ao processo formativo para profissão docente, perguntamos aos professores o que significava "tornar-se professor" e, em suas respostas, constatamos que as suas concepções relativas à identidade docente estão vinculadas, em síntese: a) a dar aulas para transmitir conhecimentos aos estudantes e; b) cooperar e aprender ao mediar a relação dos estudantes com o conhecimento, comprometendo-se com processo ensino-aprendizagem.

As respostas do primeiro grupo evidenciaram que a identidade docente é marcada pelo constructo histórico, social e cultural de que ser professor é ter a responsabilidade de reproduzir e transmitir o conhecimento. Mas, no caso do segundo grupo, também revelaram a possibilidade de mudança do e no processo ensinoaprendizagem, ao se considerarem aprendizes e mediadores na relação docentediscentes-conhecimento.

Nesse sentido, na interlocução com os docentes, observamos que o valor por eles atribuído à formação contínua está relacionado ao objeto central do trabalho por eles realizado: o ensino. Ensinar melhor e aprender a serem melhores professores foram as principais expectativas registradas por eles em relação à proposta do curso, principalmente, no que se referia aos conhecimentos relativos à prática pedagógica e novas metodologias de ensino adequadas ao novo perfil dos estudantes.

A valorização do ensino e da formação pedagógica do professor universitário demandaria, em primeiro lugar, a alteração do modo como as questões pedagógicas são entendidas e tratadas na universidade, superando a crença de que para ser bom 
professor basta conhecer profundamente e conseguir transmitir com clareza determinado conteúdo, ou, no caso mais específico do ensino superior, ser um bom pesquisador. Entretanto, a realidade concreta de muitas instituições ainda está distante do apregoado e do realizado. É certo que há algumas iniciativas pontuais nessa direção, mas o que falta é uma política consistente, sistemática e organizada.

Nesse sentido, consideramos que a participação em apenas um curso, oficina, palestra entre outras ações formativas, não é suficiente para promover alterações expressivas nas práticas docentes, mas poderão provocar inquietações, instigar reflexões que poderão reverberar no constructo identitário da profissão e promover a (trans)formação nas concepções dos professores sobre a prática pedagógica. A formação docente, enfatiza Freire (2003, p. 28), não é um processo que se restringe à formação inicial, sendo mais do que uma necessidade do professor, trata-se de uma necessidade ética da qualidade de ensino e crítica da própria atividade.

A responsabilidade ética, política e profissional do ensinante lhe coloca o dever de se preparar, de se capacitar, de se formar antes mesmo de iniciar sua atividade docente. Esta atividade exige que sua preparação, sua capacitação, sua formação se tornem processos permanentes. Sua experiência docente, se bem percebida e bem vivida, vai deixando claro que ela requer formação permanente do ensinante. Formação que se funda na análise crítica de sua prática. (FREIRE, 2003, p. 28)

No diálogo com os professores, durante as entrevistas propusemos duas questões: Quais as mudanças na sua prática pedagógica a partir de sua participação nas ações formativas? Quais as contribuições das ações formativas para o desenvolvimento de sua identidade e saberes profissionais?

$\mathrm{Na}$ opinião dos docentes, as ações formativas contribuíram para: promover a aquisição de conhecimentos e competências profissionais, quer seja ao nível da atualização das práticas profissionais, quer seja ao nível pedagógico, como também ao nível da ligação da formação com a prática para resolver problemas e identificar respostas às necessidades reais dos estudantes; adequar os conteúdos abordados com a realidade no trabalho a desenvolver com os alunos; favorecer a articulação entre formandos e formadores, tanto no que se refere aos temas ou aos conteúdos 
desenvolvidos; refletir sobre a importância e necessidade do trabalho por eles realizado, através de mecanismos de colaboração entre professores e também da discussão e reflexão das práticas profissionais; compreender a importância de se adequar a uma realidade concreta; valorizar os saberes experienciais e a possibilidade de reflexão sobre as práticas profissionais.

A docência universitária é compreendida por Almeida (2012, p. 69) como “[...] o conjunto de ações que pressupõe elementos de várias naturezas, o que impõe aos sujeitos por ela responsáveis um rol de demandas, contribuindo para configurá-la como um campo complexo de ação". Para identificar os elementos constitutivos da docência, a autora propõe três dimensões: (1) dimensão profissional - elementos da atuação profissional, identidade profissional, formação inicial ou contínua, exigências profissionais; (2) dimensão pessoal - relações de envolvimento e compromisso com a docência; (3) dimensão organizacional - condições de organização do trabalho pedagógico, viabilização e remuneração, padrões a serem atingidos na atuação profissional.

Contemplar essas dimensões no processo de formação de professores universitários constitui-se em desafios que se apresentam às instituições educacionais. É necessário reconhecer, a partir dessa premissa que, medidas simplistas não são capazes de resolver questões complexas, ou seja, será preciso instituir processos formativos baseados em princípios que realmente possibilitem uma sólida formação teórico-prática, capaz de suprir os professores com diferentes saberes profissionais para o exercício da docência. Para tanto, as instituições educacionais deverão propiciar condições efetivas, como a disponibilidade de horários, infraestrutura e incentivos para que seus professores possam e desejem investir em sua formação contínua. Consequentemente, a criação de espaços de interlocução pedagógica nas Universidades que viabilizem a troca de experiências, questionamentos e auxílio mútuo entre os docentes, são essenciais para que o lócus de atuação profissional (a Universidade) se constitua efetivamente em uma comunidade de aprendizagem, o que certamente se refletirá na qualidade do processo formativo docente e discente.

A despeito das dificuldades - em grande parte no que se refere à falta de dotação orçamentária e à escassa disponibilidade de tempo dos docentes - as atividades 
propostas e desenvolvidas foram ao encontro das necessidades dos professores, contribuindo para a sua formação contínua e para a construção sistematizada e compartilhada do conhecimento pedagógico, fomentando o diálogo e a reflexão sobre a prática docente universitária.

\section{Considerações finais}

O desenvolvimento profissional do professor na educação superior engloba a formação inicial e contínua, bem como as demais relações que estabelece com seus pares, com os estudantes, as pesquisas que realiza, as ações de extensão que promove, e deve ser compreendido a partir da concepção de práxis educativa, concebendo o ensino, a pesquisa e a extensão enquanto atividades complexas que demandam dos/as professores/as uma formação que supere o desenvolvimento de habilidades técnicas, ou o conhecimento aprofundado de um conteúdo específico. Evidentemente, o conceito de práxis aqui utilizado não é aquele que evoca a pura e simples prática, antes, porém, constitui-se como apresenta Vásquez (1977) em atividade pensada, organizada. Ao que Paulo Freire (1997, p. 38) afirma, “a práxis, porém, é reflexão e ação dos homens sobre o mundo para transformá-lo".

A partir das reflexões suscitadas pelo diálogo com dados obtidos junto aos professores que participaram de ações formativas na IFES, depreendemos que somente com a reelaboração permanente da formação, enquanto parte integrante da profissão docente e consequentemente da assunção da identidade profissional, os/as professores/as poderão definir estratégias de ação que poderão contribuir para promover mudanças significativas. A interlocução com os/as docentes nos permitiu compreender que os conceitos de formação, identidade e desenvolvimento profissional docente não são unívocos, nem preestabelecidos e estáticos; são múltiplos e oriundos de fatores, históricos, sociais, culturais e econômicos, influenciam a identidade profissional docente.

A análise das necessidades formativas elencados pelos docentes, durante as entrevistas, nos permitiu observar um ponto essencial que constitui e condiciona o desenvolvimento profissional: a fragilidade da formação específica para a docência. 
Consideramos, nesse sentido, que as ações formativas realizadas nos Cursos de Docência, alcançaram êxito, porque partiram dos interesses, das necessidades formativas explicitadas pelos docentes, porquanto as discussões suscitadas durante as ações formativas na UFU possibilitaram aos docentes refletir sobre a importância de formaremse para tornarem-se professores; ao serem convidados a narrarem sobre os seus percursos formativos e a opção pela docência, identificaram que no processo de formação inicial residiam dimensões importantes da construção de suas identidades como docentes. Esse processo deve ocorrer ao longo da vida profissional constituindo, assim, a identidade e desenvolvimento profissional docente, não obstante, se a formação for pensada de forma distanciada do contexto de trabalho, de caráter individualista a partir de modelos transmissivos, pouco tem a contribuir para o desenvolvimento profissional docente.

No diálogo com os professores que participaram das ações de formação contínua foi possível identificar que a aprendizagem da docência aconteceu na inter-relação dos processos auto e interformativos, dinamizados pela ideia do inacabamento e pela tomada de consciência da necessidade de uma formação permanente (FREIRE, 1996). Nessa perspectiva, amplia-se a compreensão do termo docência e de formação, porque permite associá-los a vários elementos conceituais como formar, educar, ensinar, aprender, compartilhar, trocar, superar, dialogar, criar, etc. É por meio do processo formativo, configurado enquanto processo dinâmico, que os sujeitos se desenvolvem ao longo da vida.

A aprendizagem profissional da docência, no âmbito universitário, precisa ser compreendida na perspectiva de processo, ou seja, uma aprendizagem que se dá durante a trajetória de vida docente e não apenas como uma etapa isolada de seu processo no percurso formativo, pois a apropriação dos conceitos científicos referentes ao desenvolvimento do trabalho docente é essencial para que se possa "avançar na compreensão da subjetividade" da ação docente, isto é, na compreensão do significado de sua ação e, necessariamente, contribuir para a constituição da autonomia e (trans)formação das concepções docentes sobre "o que pensam" e "o que realizam", a partir dessa compreensão. 
A partir das análises e reflexões oriundas do diálogo com os professores, identificamos que as ações formativas realizadas nos Cursos de Docência Universitária, Ihes possibilitou: a) reconhecerem os seus limites relativos à aquisição do saber pedagógico para o exercício do ensinar, na formação pós-graduada; b) conhecerem estratégias para redimensionar suas práticas; c) compartilharem experiências e conhecimentos, na construção de novas e atualizadas aprendizagens; d) refletirem sobre a importância de uma formação contínua, compartilhada e com significativa fundamentação teórico-científica, necessária às especificidades da prática pedagógica contextualizada no desenvolvimento do pensamento crítico diante da realidade; e) identificarem a importância das IES promoverem espaços de discussões sobre as políticas institucionais de valorização da formação contínua e do trabalho docente.

Reconhecemos, nessa perspectiva, que as ações formativas, por nós analisadas, se constituíram como possíveis estratégias de (re)elaboração do(s) saber(es) docentes, sob a ótica dos docentes que participaram das ações formativas realizadas, se configuraram em espaços formativos, capazes de fomentar a reflexão sobre a prática docente e apontar caminhos para o enfrentamento dos desafios, inerentes à docência universitária. 


\section{Referências}

ALMEIDA, Maria Isabel de. Pedagogia universitária e projetos institucionais de formação e profissionalização de professores universitários. 2011. 147 f. Tese (Livre-Docência) Faculdade de Educação, Universidade de São Paulo, São Paulo, 2011.

ALMEIDA, Maria Isabel de. Formação do professor do Ensino Superior: desafios e políticas institucionais. São Paulo: Cortez, 2012.

ALMEIDA, Maria Isabel de; PIMENTA, Selma G. Pedagogia Universitária: valorizando o ensino e a docência na Universidade de São Paulo. (Orgs.). Pedagogia Universitária. São Paulo: EDUSP, 2009.

BARDIN, Laurence. Análise do conteúdo. Lisboa: Edições Setenta, 2000.

BRASIL. Lei n. 9.394/96 de 20 de dezembro de 1996. Lei de Diretrizes e Bases da Educação Nacional. Diário Oficial da República Federativa do Brasil, Brasília, DF, n. 248, dez. 1996.

BRASIL. Resolução $\mathbf{n}^{\circ}$ 2, de $1^{\circ}$ de julho de 2015. Define as Diretrizes Curriculares Nacionais para a formação inicial em nível superior (cursos de licenciatura, cursos de formação pedagógica para graduados e cursos de segunda licenciatura) e para a formação continuada. Brasília, DF. 2015.

BEHRENS, Marilda A. O paradigma da complexidade na formação e no desenvolvimento profissional de professores universitários. Educação, Porto Alegre, ano 30, v. 63, n. 3, p. 439-455, set./dez. 2007.

CAMPOS, Vanessa T. Bueno. Marcas indeléveis da docência no ensino superior: representações relativas a docência no ensino superior de pós-graduandos de instituições federais de ensino superior. 2010. Tese (Doutorado em Educação) - Faculdade de Educação, Universidade de São Paulo, São Paulo, 2010.

\section{CAMPOS, Vanessa T. B. Ações formativas como estratégia de desenvolvimento} profissional de professores na educação superior e (trans)formação da prática docente na Universidade Federal de Uberlândia - MG. Relatório Estágio Pós-Doutoral. Faculdade de Educação. Universidade de São Paulo. São Paulo. 2017.

CHARTIER, Roger. A história cultural: entre práticas e representações. Lisboa. DIFEL. Rio de Janeiro. Editora Bertrand Brasil, 1990.

CRUZ, Manuel Fernández. Desarrollo profesional docente. Granada: Grupo Editorial Universitário. 2006.

CUNHA, Maria Isabel. Verbete Pedagogia Universitária. In: MOROSINI, Marília da C. et al. Enciclopédia de pedagogia universitária. Porto Alegre: RIES/ INEP, 2003. 
CUNHA, Maria Isabel. da. Docência na universidade, cultura e avaliação institucional: saberes silenciados em questão. Revista Brasileira de Educação, Campinas, v. 11, n. 32, p. 258-371, maio/ago. 2006.

CUNHA, Maria Isabel da. Reflexões e práticas em pedagogia universitária. Campinas: Papirus, 2007.

CUNHA, Maria Isabel da. Pedagogia universitária: energias emancipatórias em tempos neoliberais. Araraquara: Junqueira \& Marin, 2008.

CUNHA, Maria Isabel da. Ensino como mediação do professor universitário. In: MOROSINI, Marília da C. (Org.). Professor do ensino superior: docência e formação. 2. ed. Brasília: Plano Editorial, 2010.

DIFDO. Divisão de Formação Docente/ DIREN - Diretoria de Ensino/Pró-Reitoria de Graduação - PROGRAD. Universidade Federal de Uberlândia - UFU. Uberlândia, MG. Disponível em: <http://www.difdo.diren.prograd.ufu.br/principal.php>. Acesso em: maio de 2016.

FERRY, G. Pedagogía de la formación. Buenos Aires: Centro de Publicaciones Educativas y Material Didáctico, 2004.

FRANCO, Maria Laura B. Questões metodológicas e o papel do sujeito pesquisador. In: TRINDADE, Vítor; FAZENDA, Ivani; LINHARES, Célia. (Org.). Os lugares dos sujeitos na pesquisa educacional. Campo Grande: Ed. UFMS, 1999. p. 201-215

FREIRE, Paulo. Pedagogia da autonomia: saberes necessários à prática educativa. Rio de Janeiro: Paz e Terra, 1996.

FREIRE, Paulo. Pedagogia do oprimido. 24. ed. Rio de Janeiro: Paz e Terra, 1997.

FREIRE, Paulo. Pedagogia dos sonhos possíveis. São Paulo: Editora UNESP, 2001.

FREIRE, Paulo. Professora sim, tia não: cartas a quem ousa ensinar. 14. ed. São Paulo: Editora Olho d'Água, 2003.

GARCIA, Carlos Marcelo. Formação de professores: para uma mudança educativa. Porto Editora: Portugal, 1999.

HUBERMAN, Michell. O ciclo de vida profissional dos professores. In: Nóvoa, A. Vidas de professores. 2. ed. Porto: Porto Editora, 1995. p. 31-61.

IMBERNÓN, Francisco. Qualidade do ensino e formação do professorado: uma mudança necessária. São Paulo: Cortez, 2016.

LE GOFF, Jacques (Org.). A história nova. $4^{\mathrm{a}}$ ed. São Paulo: Martins Fontes, 1998. 
LEITE, Carlinda; RAMOS, Kátia M. Formação para a docência universitária: uma reflexão sobre o desafio de humanizar a cultura científica. Revista Portuguesa de Educação, Universidade do Minho: CIEd, v. 25, n. 1, 2012, p. 7-27.

MARIN, Alda. Educação continuada: introdução a uma análise de termos e concepções. In: CADERNOS CEDES: ${ }^{\circ}$ 36. Campinas, Papirus: CEDES, 1995.

MARIN, Alda Junqueira. Formação de professores: novas identidades, consciência e subjetividade. In: TIBALLI, Elianda F. Arantes, CHAVES, Sandramara M. (Orgs.).

Concepções e práticas de formação de professores: diferentes olhares. Rio de Janeiro: DP\&A, 2003. p. 57-73 (Trabalhos apresentados no XI ENDIPE - Goiânia - Goiás, 2002).

MEIRELES, Cecília. Poesias completas. Rio de Janeiro: Civilização Brasileira, 1979.

MOROSINI, Marília C. (Org.). Professor do ensino superior: identidade, docência e formação. 2. ed. Brasília: Plano, 2001.

MURILLO, Paulino Estepa. et al. Las necesidades formativas docentes de los profesores universitarios. Revista Fuentes, Sevilha: Universidade de Sevilha, v. 6, 2005, p. 1-22.

NÓVOA, António. Os professores e sua formação. Lisboa: Dom Quixote, 1992.

NÓVOA, António. Universidade e formação docente. Entrevista. Interface-Comunic, Saúde, Educ, v. 4, n. 7, 2000, p. 129-137.

NUNES, Cely do Socorro Costa. Os sentidos da formação contínua de professores: o mundo do trabalho e a formação de professores no Brasil. 2000. Tese (Doutorado em Educação) - Faculdade de Educação da Universidade Estadual de Campinas, Campinas, 2000.

PIMENTA, Selma Garrido; ANASTASIOU, Léia. das Graças Camargos. Docência no ensino superior. 4. ed. São Paulo: Cortez, 2010.

RIOS, Terezinha Azerêdo. Compreender e ensinar: por uma docência da melhor qualidade. 3. ed. São Paulo: Cortez, 2002.

RIOS, Terezinha Azerêdo. Ética na docência universitária: a caminho de uma universidade pedagógica? In: CADERNOS DE PEDAGOGIA UNIVERSITÁRIA. Universidade de São Paulo: Pró-Reitoria de Graduação, 2009.

RODRIGUES, Ângela; ESTEVES, Manuela. A análise de necessidades na formação de professores. Porto: [s.n.], 1993 . Coleção ciências da educação.

SIKES, Pat The life cycle of the teacher. In: Ball, Stephen; Goodson, Ivor (Ed.). Teachers lives and careers. London: The Falmer Press, 1985. p. 67-70. 
SOARES, Sandra Regina; CUNHA, Maria Isabel da. Programas de Pós-Graduação em Educação: lugar de formação da docência universitária? Revista Brasileira de PósGraduação, Brasília, v. 7, n. 14, p. 577-604, dez. 2010.

VEIGA, Ilma Passos Alencastro. Docência universitária na educação superior. In: RISTOFF, Dilvo; SEVEGNANI, Palmira (Orgs.). Docência na educação superior. Brasília: Instituto Nacional de Estudos e Pesquisas Anísio Teixeira, 2006. Coleção Educação Superior em Debate; v. 5 .

VAILLANT, Denise; MARCELO, Carlos. Ensinando a ensinar: as quatro etapas de uma aprendizagem. Curitiba: Editora UTFPR, 2012.

VÁSQUEZ, Adolfo Sánchez. Filosofia da práxis. Rio de Janeiro: Paz e Terra, 1977.

ZABALZA, Miguel Angel. O ensino universitário: seu cenário e seus protagonistas. Porto Alegre: Artmed, 2004. 